\title{
The footprint of humans with serious psychological distress: a cross-sectional study of 1.5 million adults in the United States
}

\section{BACKGROUND}

This study investigates the prevalence of serious psychological distress (SPD) in the United States during 20122018 as well as the characteristics of people with SPD with the ultimate goal to find statistically significant indicators for SPD.

\section{PARTICIPANTS AND PROCEDURE}

The statistical methods used to analyze the results of this study are the chi-square and one-way analysis of variance (ANOVA) tests. Additionally, a multiple logistic regression analysis was used with the odds ratio (OR) to find statistically significant prognostic factors for SPD.

\section{RESULTS}

The prevalence of SPD was found to be $3.4 \%$. The number of individuals with SPD increased from 2012 to 2018 by $34.1 \%$. As indicated by multiple logistic regression analyses, individuals who have less than $\$ 35000$ family income have six times higher risk of SPD occurring $(\mathrm{OR}=6.31)$, while white females $(O R=1.93)$ in the age group of $45-64$ $(\mathrm{OR}=2.01)$ who are not employed but have worked previously $(\mathrm{OR}=1.25)$, and are divorced or separated $(\mathrm{OR}=1.57)$ have a two-fold higher risk for the occurrence of this type of disorder. In addition, the risk of SPD is fivefold higher in poor individuals $(\mathrm{OR}=4.81)$ with inadequate education $(\mathrm{OR}=5.44)$.

\section{CONCLUSIONS}

The results of this study explain the significance of deprivation (of financial comfort, education, husband, and work) as the main prognostic risk factor for SPD. Moreover, individuals with SPD are more likely to be white females in the age group of 45-64.

KEY WORDS

serious psychological distress; prognostic factors; socioeconomic factors 


\section{BACKGROUND}

Serious psychological distress (SPD) includes serious mental health problems that cause social and occupational dysfunction and require treatment (Pratt, Dey, $\&$ Cohen, 2007). It is characterized by depressive and anxiety symptoms, and is an indication of common psychiatric conditions such as depression and anxiety disorders (Mirowsky \& Ross, 2002). The six-item Kessler psychological scale (K6) has been developed for the assessment of SPD (Kessler et al., 2002). It has been demonstrated that the K6 has a sensitivity of 0.34 and specificity of 0.96 at a cut-point of $\geq 13$ to identify psychological distress associated with common mental illness (Kessler et al., 2003). Recent studies have reported an alarming increase in SPD levels in adults in the United States (Case \& Deaton, 2015; Curtin, Warner, \& Hedegaard, 2016b). More specifically, the annual rates of US adults who receive outpatient mental health care have risen from 5.0\% (2008-2009) to $5.7 \%$ (2014-2015) (Han, Olfson, Huang, \& Mojtabai, 2017), while the rate of using antidepressants has risen from $6.4 \%$ (2000-2002) to $10.7 \%$ (2011-2014), and the corresponding rate of using anxiolytics/hypnotics increased from $3.3 \%$ to $5.3 \%$ (National Center for Health Statistics, 2016). There has also been reported an increase in national suicide rates (Curtin, Warner, \& Hedegaard, 2016a), opioid use (Dart et al., 2015), and opioid-related deaths, reflecting a further increase in SPD. Prior studies have linked SPD with financial stress (Yang \& Yang, 1992; Case \& Deaton, 2015; Weissman, Russell, Jay, \& Malaspina, 2018). More precisely, financial stress due to a reduction in wealth has been proved to be the cause of poorer mental and physical health (Case \& Deaton, 2015). Moreover, US adults with SPD are more likely to announce that they have not recovered from the 2008-2009 recession and they are having trouble accessing health care and prescriptions due to cost (Weissman et al., 1997).

Previous studies have shown a strong link between SPD and mortality in people with lower socioeconomic status (Smith, Hart, Blane, Gillis, \& Hawthorne, 2017; Mackenbach et al., 2003; Lazzarino, Hamer, Stamatakis, \& Steptoe, 2013a, 2013b). Unemployment has been reported to be a risk factor for SPD, while white adults with a low educational level are more likely to have SPD (Weissman, Russell, \& Mann, 2020). In addition, adults with SPD are more likely to be uninsured (Garfield, Zuvekas, Lave, \& Donohue, 2011), and to experience delays in health care (Weissman et al., 2017). Finally, individuals with SPD are more likely to suffer from chronic diseases such as cardiovascular disease, chronic obstructive pulmonary disease, and diabetes (Weissman, Pratt, Miller, \& Parker, 2015).

It is of the utmost importance to acknowledge the seriousness of SPD in adults, which in return reflects the responsibility of underlying factors that lead to barriers to mental health. For this purpose, this study investigates SPD in the United States during the period 2012-2018 to identify the underlying factors with the highest risk for SPD.

\section{PARTICIPANTS AND PROCEDURE}

\section{PARTICIPANTS AND MEASURES}

The data used in this work originate from the National Health Interview Survey dataset (National Center for Health Statistics, 2016) and cover the period 20122018. The data were available for each year. SPD was measured with the Kessler 6 scale (K-6). To identify the adults with SPD, each household was asked to answer how often in the past 30 days they had felt sadness, hopelessness, worthlessness, that everything is an effort, nervousness, and restlessness. Respondents could choose among five response categories: "All of the time", "Most of the time", "Some of the time", "A little of the time", or "None of the time". Responses to the questions regarding feelings of sadness, hopelessness, worthlessness, that everything is an effort, nervousness, and restlessness were combined to create an indicator of serious psychological distress. The total number of adults examined was 1697 236, while the number of individuals with SPD was 57259.

\section{STATISTICAL ANALYSIS}

The statistical methods used to extract the results of this work are the $\chi^{2}$ test for categorical and one-way analysis of variance (ANOVA) for continuous variables in order to evaluate the null hypothesis that the mean number of adults in the United States with SPD did not differ according to their socio-economic characteristics such as gender, age, race, origin, parent's education, family income, poverty status, health insurance coverage, current health status, family structure, place of residence and region. Predictive factors that determine the prevalence of SPD were assessed using multiple logistic regression analysis. To assess the predictors of SPD, we used data on adults with a new diagnosis of SPD compared to a matched cohort of adults without SPD. In particular, the control group was all the target population without SPD with the same socioeconomic characteristics as the group of adults with SPD. Predictors were represented using the odds ratio (OR) and 95\% confidence intervals and $p<.05$ was considered as statistically significant. To be more specific, the OR was used to determine whether a particular characteristic is a risk factor for SPD, and to compare the magnitude of various risk factors for that outcome. An OR > 1.00 means that the characteristic is associated with higher odds of outcome and finally an $\mathrm{OR}<1.00$ implies that the characteristic is associated with lower odds of the
Serious
psychological
distress 
outcome (Szumilas, 2010). The study was carried out using the IBM SPSS 25 software package for Windows. The data were weighted before being analyzed.

\section{RESULTS}

To test the null hypothesis that the mean number of US patients with SPD did not differ in accordance with their socio-economic characteristics, the chisquare test and the one-way analysis of variance (ANOVA) were used. As shown in Table 1, there is a statistically significant difference in the number of SPD in relation to gender and it occurs mainly in women $(61.7 \%)$. Additionally, the age with the more frequent occurrence of SPD is from 18 to 44 years old (43.6\%), while the most common origin and race are white $(83.7 \%)$, not Hispanic or Latino (45.3\%).
Irene Rethemiotaki
Table 1

Chi-square and one-way ANOVA test

\begin{tabular}{|c|c|c|c|}
\hline $\begin{array}{l}\text { Characteristics of patients with serious psychological } \\
\text { distress: United States 2012-2018 }\end{array}$ & Number of patients & $\%$ & $p$-value \\
\hline Gender & & & $<.001$ \\
\hline Male & 21944 & 38.32 & \\
\hline Female & 35315 & 61.68 & \\
\hline Age (years) & & & $<.001$ \\
\hline $18-44$ & 24948 & 43.57 & \\
\hline $45-64$ & 24606 & 42.97 & \\
\hline $65-74$ & 4829 & 8.43 & \\
\hline 75 and over & 2879 & 5.03 & \\
\hline Race & & & $<.001$ \\
\hline White & 45044 & 83.75 & \\
\hline Black or African American & 6962 & 12.94 & \\
\hline Asian & 1779 & 3.31 & \\
\hline Origin & & & $<.001$ \\
\hline Hispanic or Latino & 8882 & 8.49 & \\
\hline Mexican or Mexican American & 5348 & 5.11 & \\
\hline Not Hispanic or Latino & 47379 & 45.29 & \\
\hline White single race & 36386 & 34.78 & \\
\hline Black or African American, single race & 6616 & 6.32 & \\
\hline Education & & & $<.001$ \\
\hline Less than a high school diploma & 12361 & 24.43 & \\
\hline High school diploma & 15903 & 31.43 & \\
\hline Some college & 15866 & 31.36 & \\
\hline Bachelor's degree or higher & 6469 & 12.78 & \\
\hline Employment & & & $<.001$ \\
\hline Employed & 18644 & 24.75 & \\
\hline Full-time & 12656 & 16.80 & \\
\hline Part-time & 5439 & 7.22 & \\
\hline Not employed but has worked previously & 33982 & 45.12 & \\
\hline Not employed and has never worked & 4602 & 6.11 & \\
\hline
\end{tabular}


Table 1

(Table 1 continued)

\begin{tabular}{|c|c|c|c|}
\hline $\begin{array}{l}\text { Characteristics of patients with serious psychological } \\
\text { distress: United States 2012-2018 }\end{array}$ & Number of patients & $\%$ & $p$-value \\
\hline Family income & & & $<.001$ \\
\hline Less than $\$ 35,000$ & 31709 & 42.83 & \\
\hline$\$ 35,000$ or more & 21628 & 29.21 & \\
\hline$\$ 35,000-\$ 49,999$ & 5682 & 7.67 & \\
\hline$\$ 50,000-\$ 74,999$ & 6775 & 9.15 & \\
\hline$\$ 75,000-\$ 99,999$ & 3540 & 4.78 & \\
\hline$\$ 100,000$ or more & 4704 & 6.35 & \\
\hline Poverty status & & & $<.001$ \\
\hline Poor & 17436 & 32.05 & \\
\hline Near poor & 15368 & 28.25 & \\
\hline Not poor & 21600 & 39.70 & \\
\hline \multicolumn{4}{|l|}{ Health insurance coverage } \\
\hline Under 65 & & & $<.001$ \\
\hline Private & 17078 & 34.63 & \\
\hline Medicaid & 15745 & 31.93 & \\
\hline Other coverage & 5878 & 11.92 & \\
\hline Uninsured & 10615 & 21.52 & \\
\hline 65 and over & & & $<.001$ \\
\hline Private & 2158 & 32.82 & \\
\hline Medicaid & 1555 & 23.65 & \\
\hline Other coverage & 2071 & 31.49 & \\
\hline Uninsured & 792 & 12.04 & \\
\hline Marital status & & & $<.001$ \\
\hline Married & 20029 & 35.03 & \\
\hline Widowed & 4083 & 7.14 & \\
\hline Divorced or separated & 12386 & 21.66 & \\
\hline Never married & 15366 & 26.88 & \\
\hline Living with a partner & 5309 & 9.29 & \\
\hline Place of residence & & & $<.001$ \\
\hline Large MSA (population size 1 million or more) & 25053 & 46.20 & \\
\hline Small MSA (less than 1 million) & 18247 & 33.65 & \\
\hline Not in MSA & 10928 & 20.15 & \\
\hline Region & & & $<.001$ \\
\hline Northeast & 8759 & 16.00 & \\
\hline Midwest & 12885 & 23.53 & \\
\hline South & 19617 & 35.83 & \\
\hline West & 13496 & 24.65 & \\
\hline
\end{tabular}

Note. MSA - metropolitan statistical area. 
One third of patients with SPD have a high school diploma (31.4\%) and they are not employed but have worked previously $(45.1 \%)$. Moreover, $35 \%$ of patients are married, not poor $(39.7 \%)$, with a family income of less than $\$ 35000$ (42.8\%). Health insurance coverage which is statistically significant in both age groups under $65(34.6 \%)$ and 65 and over (32.8\%) is private. Finally, the region with the most frequent occurrence of SPD is the South (35.8\%), in a place of residence with a population size of one million or more $(46.2 \%)$.

Table 2 shows the multiple logistic regression analysis with the odds ratios to find the predictors for the occurrence of SPD. As can be seen in Table 2, all prognostic factors are statistically significant $(p<0.05)$, except origin. Based on multiple logistic regression, the risk of SPD is significantly higher with the female gender $(\mathrm{OR}=1.00)$, age 45-64
Irene Rethemiotaki

Table 2

Statistically significant predictors of serious psychological distress using multivariate logistic regression

\begin{tabular}{|c|c|c|c|c|}
\hline $\begin{array}{l}\text { Socio-economic characteristics of patients: } \\
\text { United States 2012-2018 }\end{array}$ & Patients & Controls & OR $(95 \% \mathrm{Cl})$ & $p$-value \\
\hline Gender & & & & $<.001$ \\
\hline Male & 21944 & 795532 & $0.66(0.64-0.67)$ & \\
\hline Female & 35315 & 844445 & $1.00($ ref $)$ & \\
\hline Age (years) & & & & $<.001$ \\
\hline $18-44$ & 24948 & 764757 & $1.48(1.42-1.54)$ & \\
\hline $45-64$ & 24606 & 555797 & $2.01(1.93-2.09)$ & \\
\hline $65-74$ & 4829 & 186471 & $1.17(1.12-1.23)$ & \\
\hline 75 and over & 2879 & 131112 & 1.00 (ref) & \\
\hline Race & & & & $<.001$ \\
\hline White & 45044 & 1292323 & $1.93(1.84-2.02)$ & \\
\hline Black or African American & 6962 & 200113 & $1.92(1.82-2.03)$ & \\
\hline Asian & 1779 & 98580 & $1.00($ ref $)$ & \\
\hline Origin & & & & .534 \\
\hline Hispanic or Latino & 8882 & 255041 & $1.00(0.97-1.03)$ & \\
\hline Mexican or Mexican American & 5348 & 155300 & $0.99(0.95-1.03)$ & \\
\hline Not Hispanic or Latino & 47379 & 1384456 & $0.98(0.96-1.01)$ & \\
\hline White single race & 36386 & 1063656 & $0.98(0.96-1.01)$ & \\
\hline Black or African American, single race & 6616 & 191026 & $1.00($ ref $)$ & \\
\hline Education & & & & $<.001$ \\
\hline Less than a high school diploma & 12361 & 173601 & $5.44(5.28-5.61)$ & \\
\hline High school diploma & 15903 & 348820 & $3.48(3.38-3.59)$ & \\
\hline Some college & 15866 & 411360 & $2.94(2.86-3.03)$ & \\
\hline Bachelor's degree or higher & 6469 & 494683 & $1.00($ ref $)$ & \\
\hline Employment & & & & $<.001$ \\
\hline Employed & 18644 & 1026651 & $0.35(0.33-0.36)$ & \\
\hline Full-time & 12656 & 833876 & $0.29(0.28-0.30)$ & \\
\hline Part-time & 5439 & 178499 & $0.58(0.56-0.61)$ & \\
\hline Not employed but has worked previously & 33982 & 521994 & $1.25(1.21-1.29)$ & \\
\hline Not employed and has never worked & 4602 & 88653 & $1.00($ ref $)$ & \\
\hline
\end{tabular}

(Table 2 continues) 
Table 2

(Table 2 continued)

\begin{tabular}{|c|c|c|c|c|}
\hline $\begin{array}{l}\text { Socio-economic characteristics of patients: } \\
\text { United States 2012-2018 }\end{array}$ & Patients & Controls & OR $(95 \% \mathrm{Cl})$ & $p$-value \\
\hline Family income & & & & $<.001$ \\
\hline Less than $\$ 35,000$ & 31709 & 438328 & $6.31(6.12-6.51)$ & \\
\hline$\$ 35,000$ or more & 21628 & 1045979 & $1.80(1.74-1.86)$ & \\
\hline$\$ 35,000-\$ 49,999$ & 5682 & 184037 & $2.69(2.59-2.80)$ & \\
\hline$\$ 50,000-\$ 74,999$ & 6775 & 260445 & $2.27(2.18-2.35)$ & \\
\hline$\$ 75,000-\$ 99,999$ & 3540 & 191856 & $1.61(1.54-1.68)$ & \\
\hline$\$ 100,000$ or more & 4704 & 410570 & 1.00 (ref) & \\
\hline Poverty status & & & & $<.001$ \\
\hline Poor & 17436 & 182816 & $4.81(4.71-4.91)$ & \\
\hline Near poor & 15368 & 266953 & $2.90(2.84-2.96)$ & \\
\hline Not poor & 21600 & 1089447 & 1.00 (ref) & \\
\hline Health insurance coverage & & & & $<.001$ \\
\hline \multicolumn{5}{|l|}{ Under 65} \\
\hline Private & 17078 & 907115 & $0.34(0.34-0.35)$ & \\
\hline Medicaid & 15745 & 150395 & $1.94(1.89-1.99)$ & \\
\hline Other coverage & 5878 & 58348 & $1.86(1.80-1.93)$ & \\
\hline Uninsured & 10615 & 196817 & 1.00 (ref) & \\
\hline 65 and over & & & & $<.001$ \\
\hline Private & 2158 & 144557 & $0.47(0.44-0.51)$ & \\
\hline Medicaid & 1555 & 20926 & $2.38(2.18-2.59)$ & \\
\hline Other coverage & 2071 & 75211 & $0.88(0.81-0.95)$ & \\
\hline Uninsured & 792 & 25371 & $1.00(\mathrm{ref})$ & \\
\hline Marital status & & & & $<.001$ \\
\hline Married & 20029 & 875011 & $0.52(0.50-0.53)$ & \\
\hline Widowed & 4083 & 96321 & $0.96(0.92-1.00)$ & \\
\hline Divorced or separated & 12386 & 178583 & $1.57(1.52-1.63)$ & \\
\hline Never married & 15366 & 365362 & $0.95(0.92-0.98)$ & \\
\hline Living with a partner & 5309 & 120725 & $1.00($ ref) & \\
\hline Place of residence & & & & $<.001$ \\
\hline Large MSA (population size 1 million or more) & 25053 & 914192 & $0.57(0.56-0.59)$ & \\
\hline Small MSA (less than 1 million) & 18247 & 496865 & $0.77(0.75-0.79)$ & \\
\hline Not in MSA & 10928 & 230475 & $1.00($ ref $)$ & \\
\hline Region & & & & $<.001$ \\
\hline Northeast & 8759 & 292683 & $0.84(0.82-0.86)$ & \\
\hline Midwest & 12885 & 366758 & $0.98(0.96-1.01)$ & \\
\hline South & 19617 & 601673 & $0.91(0.89-0.93)$ & \\
\hline West & 13496 & 379889 & 1.00 (ref) & \\
\hline
\end{tabular}

Note. MSA - metropolitan statistical area. 
$(\mathrm{OR}=2.01)$, white race $(\mathrm{OR}=1.93)$, and "less than a high school diploma" education status $(\mathrm{OR}=5.44)$. Moreover, those who are not employed but have worked previously have a higher risk of developing SPD (OR = 1.25). In addition, the risk of SPD is six-fold higher with the family income "less than $\$ 35000$ " (OR = 6.31), five-fold higher with the poverty status "poor" $(\mathrm{OR}=4.81)$, and two-fold higher with health insurance coverage "Medicaid" under 65 years old and "Medicare and Medicaid" over 65 years old $(\mathrm{OR}=1.94$ and 2.38 respectively). Individuals who are divorced or separated have almost a two-fold higher risk of developing SPD (OR = 1.57). Finally, the risk of SPD is significantly higher with the region "West" $(\mathrm{OR}=1.00)$ and place of residence "not in a metropolitan statistical area” $(\mathrm{OR}=1.00)$.

Figure 1 represents the trend in SPD as well as the trend in education, family income, employment and

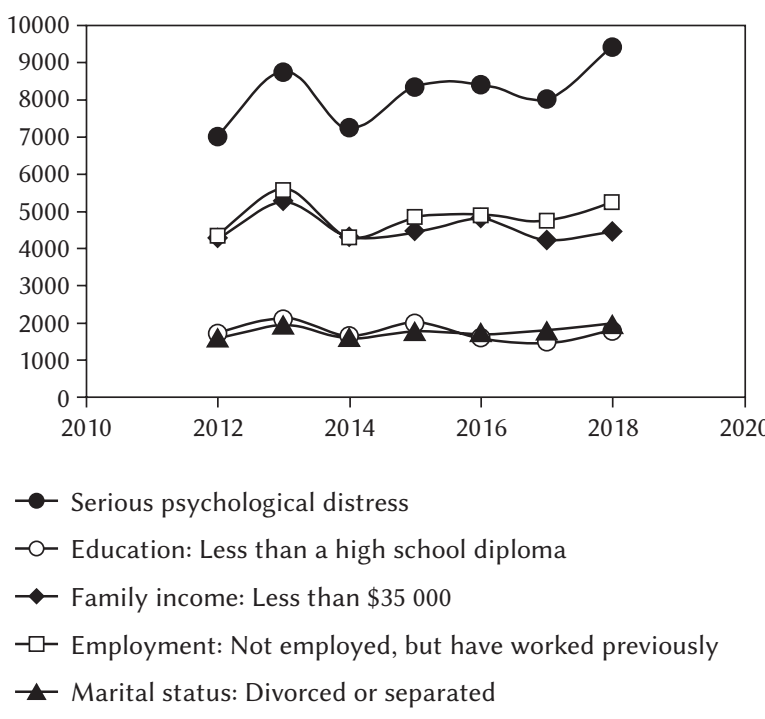

Figure 1. The trend in serious psychological distress as well as the trend in education, family income, employment and marital status with the highest OR during the years 2012-2018 in the United States. marital status with the highest OR during the years 2012-2018 in the United States. The occurrence of SPD increased from 2012 to 2018 by $34.1 \%$. The prevalence of SPD in these seven years was found to be $3.4 \%$. Figure 2 represents the prognostic risk factors with the odds ratios for SPD. As can be seen, family income ranks first, followed by education status, and poverty status.

\section{DISCUSSION}

It is worth noting that the socioeconomic characteristic of patients with the highest risk is family income and more specifically, it has been found that individuals with less than $\$ 35000$ family income have six times higher risk of developing SPD $(\mathrm{OR}=6.31)$. Additionally, education level plays a key role in the occurrence of this type of disorder. Individuals with the lowest education level have five times the risk of having SPD $(\mathrm{OR}=5.44)$. This can be explained by the fact that the lack of education reflects problems in vocational rehabilitation. Moreover marital status and employment are crucial factors in human psychology. Divorced or separated individuals have an almost two-fold higher risk of developing SPD (OR = 1.57). This can be explained by the fact that the lack of a husband reflects problems in the psychopathology of the partner such as higher levels of depression, and fear, as well as lower levels of self-esteem (Strohschein, McDonough, MonettMe, \& Shao, 2005). Combining, however, the higher risk of individuals who are not employed $(\mathrm{OR}=1.25)$, the lack of a husband reflects the financial distress faced by these people.

It is also noted that the number of patients with serious psychological distress in the United States during the years 2012-2018 increased at an alarming rate of $34.1 \%$. The prevalence of SPD was found to be $3.4 \%$, while in the previous years (2009-2013) it was estimated at 3.3\% (Weissman et al., 2015), that is, it increased slightly. Factors influencing the prevalence of SPD in the United States have been found to be the same as in other regions, such as Japan, Panama, and Bangladesh,

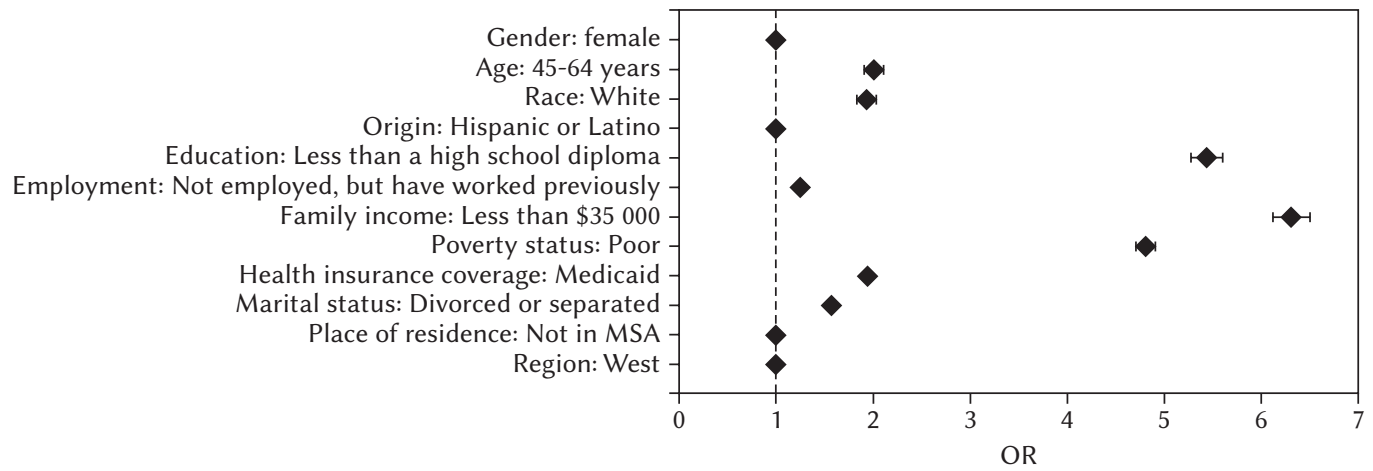

Figure 2. Prognostic risk factors with odds ratios for serious psychological distress. 
where SPD was estimated at a greater percentage of $4 \%, 6 \%$, and $9 \%$ respectively. More specifically, factors including female gender, lower level of education, inability to work, and living in semi-urban areas were associated with a higher prevalence of SPD (Nishi, Susukida, Usuda, Mojtabai, \& Yamanouchi, 2018; Walker, Campbell, Dawson, \& Egede, 2019; Islam, 2019).

This study's importance lies in the interaction of multiple socio-economic variables with SPD, which reflects the complexity and multidimensional nature of deprivation, as well as the various roles of these dimensions during the course of life, which in turn reflects the longest gestation period for SPD.

\section{CONCLUSIONS}

This paper highlights that different socioeconomic variables are associated with different SPD risks, while deprivation (of financial comfort, education, husband, and work) proved to be the main prognostic risk factor for SPD. Moreover, individuals with SPD are more likely to be white females in the age group of 45-64.

\section{RefERENCES}

Case, A., \& Deaton, A. (2015). Rising morbidity and mortality in midlife among white non-Hispanic Americans in the 21st century. Proceeding of the National Academy of Sciences, 112, 15078-15083.

Curtin, S. C., Warner, M., \& Hedegaard, H. (2016a). Suicide rates for females and males by race and ethnicity: United States, 1999 and 2014. NCHS health E-stat. National Center for Health Statistics.

Curtin, S. C., Warner, M., \& Hedegard, H. (2016b). Increase in Suicide in the United States, 1999-2014. NCHS Data Brief; no 241. Hyattsville, MD: National Center for Health Statistics.

Dart, R. C., Surratt, H. L., Cicero, T. J., Parrino, M. W., Severtson, S. G., Bucher-Bartelson, B., \& Green, J. L. (2015). Trends in opioid analgesic abuse and mortality in the United States. The New England Journal of Medicine, 372, 241-248.

Garfield, R. L., Zuvekas, S. H., Lave, J. R., \& Donohue, J. M. (2011). The impact of national health care reform on adults with severe mental disorders. American Journal of Psychiatry, 168, 486-494.

Han, B., Olfson, M., Huang, L., \& Mojtabai, R. (2017). National trends in specialty outpatient mental health care among adults [published correction appears in Health Aff (Millwood). 2018;37(2):336]. Health Aff (Millwood), 36, 2062-2068.

Islam, F. M. A. (2019). Psychological distress and its association with socio-demographic factors in a rural district in Bangladesh: A cross-sectional study. PLoS One, 14, e0212765.
Kessler, R. C., Andrews, G., Colpe, L. J., Hiripi, E., Mroczek, D. K., Normand, S. L. T., Walters, E. E., \& Zaslavsky, A. M. (2002). Short screening scales to monitor population prevalences and trends in non-specific psychological distress. Psychological Medicine, 32, 959-976.

Kessler, R. C., Barker, P. R., Colpe, L. J., Epstein, J. F., Gfroerer, J. C., Hiripi, E., Howes, M. J., Normand, S. L., Manderscheid, R. W., Walters, E. E., \& Zaslavsky, A. M. (2003). Screening for Serious Mental Illness in the General Population. Archives of General Psychiatry, 60, 184-189.

Lazzarino, A. I., Hamer, M., Stamatakis, E., \& Steptoe, A. (2013a). Low socioeconomic status and psychological distress as synergistic predictors of mortality from stroke and coronary heart disease. Psychosomatic Medicine, 75, 311-316.

Lazzarino, A. I., Hamer, M., Stamatakis, E., \& Steptoe, A. (2013b). The combined association of psychological distress and socioeconomic status with all-cause mortality. JAMA Internal Medicine, 173, 22-27.

Mackenbach, J. P., Bos, V., Andersen, O., Cardano, M., Costa, G., Harding, S., Reid, A., Hemström, O., Valkonen, T., \& Kunst, A. E. (2003). Widening socioeconomic inequalities in mortality in six Western European countries. International Journal of Epidemiology, 32, 830-837.

Mirowsky, J., \& Ross, C. E. (2002). Measurement for a human science. Journal of Health and Social Behavior, 43, 152-170.

National Center for Health Statistics, Centers for Disease Control and Prevention. Health, United States, 2016 - individual charts and tables: spreadsheet, PDF, and PowerPoint files. Table 080. https://www. cdc.gov/nchs/hus/contents2016.htm\#080 (accessed May 2, 2019).

National Center for Health Statistics. (2016). Data file documentation, National Health Interview Survey. Available from: https://www.cdc.gov/nchs/nhis.htm.

Nishi, D., Susukida, R., Usuda, K., Mojtabai, R., \& Yamanouchi, Y. (2018). Trends in the prevalence of psychological distress and the use of mental health services from 2007 to 2016 in Japan. Journal of Affective Disorders, 239, 208-213.

Pratt, L. A., Dey, A. N., \& Cohen, A. J. (2007). Characteristics of adults with serious psychological distress as measured by the K6 scale: United States, 2001-04. Advance data from vital and health statistics; no 382. Hyattsville, MD: National Center for Health Statistics.

Smith, G. D., Hart, C., Blane, D., Gillis, C., \& Hawthorne, V. (1997). Lifetime socioeconomic position and mortality: prospective observational study. British Medical Journal, 314, 547-552.

Strohschein, L., McDonough, P., Monette, G., \& Shao, Q. (2005). Marital transitions and mental health: Are there gender differences in the short-term effects of
Serious psychological distress 
marital status change? Social Science \& Medicine, 61, 2293-2303.

Szumilas, M. (2010). Explaining odds ratios [published correction appears in J Can Acad Child Adolesc Psychiatry. 2015 Winter;24(1):58]. Journal of the Canadian Academy of Child and Adolescent Psychiatry, 19, 227-229.

Walker, R. J., Campbell, J. A., Dawson, A. Z., \& Egede, L. E. (2019). Prevalence of psychological distress, depression and suicidal ideation in an in-

Irene digenous population in Panamá. Social Psychiatry Rethemiotaki and Psychiatric Epidemiology, 54, 1199-1207.

Weissman, J., Pratt, L. A., Miller, E. A., \& Parker, J. D. (2015). Serious psychological distress among adults: United States, 2009-2013. NCHS Data Brief, 203, 1-8.

Weissman, J., Russell, D., Jay, M., \& Malaspina, D. (2018). Race, ethnic and gender disparities in access and health care utilization among adults with serious psychological distress in the United States. Psychiatric Services, 69, 517-522.

Weissman, J., Russell, D., Jay, M., Beasley, J. M., Malaspina, D., \& Pegus, C. (2017). Disparities in healthcare utilization and functional limitations in adults with serious psychological distress in the United States, findings from the NHIS: 2006-2014. Psychiatric Services, 68, 653-659.

Weissman, J., Russell, D., \& Mann, J. J. (2020). Sociodemographic characteristics, financial worries and serious psychological distress in U.S. adults. Commun Ment Health J, 56, 606-613. https://doi. org/10.1007/s10597-019-00519-0

Yang, B., \& Yang, L. D. (1992). Sociological and ecological theories of suicide: A comparison of the U.S.A. and Taiwan. Social Science and Medicine, 34, 333-334. 